\title{
Alternative ways to correct poor glucose metabolism in patient with diabetes mellitus
}

\author{
Leonid Sevastyanov ${ }^{1}$, Yermek Turgunov ${ }^{1}$, Jean-Pierre Faure ${ }^{2}$, Dmitriy Shestakov ${ }^{1}$ \\ ${ }^{1}$ Karaganda Medical University, Kazakhstan \\ ${ }^{2}$ University of Poitiers, France
}

Received: 2021-08-09

Accepted: 2021-09-27

This work is licensed under Creative Commons Attribution 4.0 International License

J Clin Med Kaz 2021; 18(5):30-34

Corresponding author:

Leonid Sevastyanov.

Email: Sevastyanov@kgmu.kz;

ORCID: 0000-0002-8071-8690

\section{Abstract}

There is an annual increase in the incidence of diabetes recorded worldwide. The existing measures of prevention and multimodal treatment of the disease have not yet brought the desired results. A promising field is bariatric (metabolic) operations used in obese patients, which also improve glucose metabolism in the case of concomitant diabetes mellitus of both types 1 and 2. At the same time, there is a certain contradiction and understatement regarding the mechanisms that lead to remission of diabetes mellitus, regardless of weight loss. One of the anatomical effects of bariatric procedures is the accelerated release of nutrients into the distal segment of the small intestine, which leads to stimulation of enteroendocrine cells and increased secretion of incretins (GLP-1, PYY, etc.). The experiment investigates these mechanisms by the operation of ileal transposition. Further study of the ileal transposition effects using different models of type 1 and type 2 diabetes, accompanied both with and without obesity, may contribute to a more detailed understanding of the triggering and supporting mechanisms of increasing glucose tolerance in the struggle against this disease.

Key words: diabetes mellitus, metabolic surgery, ileal transposition

\section{Introduction}

Diabetes mellitus is a chronic, progressive, widespread disease, with a steady upward trend worldwide. Various aspects of diabetes are well described: morbidity, early and late complications of the disease, impact on the quality of life and health care costs, mortality, etc.

The International Diabetes Federation (IDF) assessed the overall prevalence of diabetes mellitus: if in 2011, it was diagnosed in 366 million patients, then by 2030, it is projected to be found in 552 million patients. According to WHO, in 2014, the number of patients was 442 million adults, compared to 1980 , when the number of people suffering from this disease was 108 million $[1,2]$.

Every year, huge funds are allocated for the treatment of diabetes. In total, $\$ 760$ billion was spent worldwide in 2019 to combat this disease [3].

It is shown that patients with diabetes mellitus have a high risk of disability and cardiovascular diseases, compared with people who do not suffer from this pathology. Moreover, this risk tends to increase over time since the lack of good metabolic control, which is evidenced by constantly increased levels of glycosylated hemoglobin (HbAlc), inevitably leads to complications: diabetic nephropathy, diabetic retinopathy, diabetic neuropathy, as well as macrovascular problems [4].

The coronavirus pandemic has forced a new insight into diabetes mellitus as a life-threatening situation when combined with COVID-19. There are indications that diabetes is not a risk factor for COVID-19 but it has an aggravating effect on its course and outcome [5].

Treatment of patients with diabetes, of course, leads to an improvement in their condition and gives a certain economic effect [6]. However, physiological and, therefore, the most affordable measures, i.e. changing the lifestyle and diet, do not achieve significant long-term results [7] and drug therapy only causes compensation in $30 \%$ of patients, while remission is achieved only in a minimal number of patients [8].

Therefore, the relevance of the problems of diabetes mellitus today remains high. Efforts to solve these problems should probably be aimed at searching for new methods of treating and preventing the development of diabetes using advanced technologies. 


\section{Effect of Bariatric Operations on Glucose Metabolism.}

Recent studies have revealed and, subsequently, confirmed the positive effect of bariatric operations in patients with type 2 diabetes mellitus (DM2), both with and without obesity. Bariatric operations (baros = weight) is a surgical procedure performed on the gastrointestinal tract in patients with pathological obesity. Such operations are often referred to as metabolic operations because of their positive effects: weight loss and improved metabolic control, especially in patients with DM2. Obviously, these effects have allowed several authors to consider a bariatric surgery as an alternative to pharmacological treatment, which can help to correct overweight, control hyperglycaemia, and achieve remission of the disease [9-20]. A number of studies have shown that surgical methods were successful and improved the condition of patients with diabetes mellitus of type 1 (DM1) [21-23] (Table 1).

Table 1 Bariatric surgery and diabetes: literature review results

\begin{tabular}{|c|c|c|c|c|c|}
\hline Procedure & Procedure & $\begin{array}{l}\text { Following time } \\
\text { (years) }\end{array}$ & $\mathrm{HbA1c}$ & $(\%)$ & Remarks \\
\hline Adams et al.[15] & $\begin{array}{l}418 \text { RYGB ( } 93 \text { T2DM) } 417 \text { nonsurgical } \\
\text { obese control } \\
\text { (106 T2DM } 321 \text { population-based } \\
\text { control ( } 92 \text { T2DM) }\end{array}$ & 6 & $<6.5$ & $\begin{array}{l}62 \% \text { complete } \\
\text { remission }\end{array}$ & $\begin{array}{l}\text { Better control of bypass } \\
\text { than nonsurgical group } \\
\text { Mean BMI } 45.9\end{array}$ \\
\hline Arterburn et al.[16] & 4434 RYGB & 5 & $<6$ & $\begin{array}{l}68 \% \text { complete } \\
9 \% \text { partial }\end{array}$ & Retrospective cohort \\
\hline Cohen et al.[17] & 66 RYGB & 6 & $<6.5$ & $\begin{array}{l}88 \% \text { complete } \\
11 \% \text { partial }\end{array}$ & $30<\mathrm{BMI}<35$ \\
\hline Lakdawala et al.[18] & 52 RYGB & 5 & $<7$ & $\begin{array}{l}58 \% \text { complete } \\
38 \% \text { partial }\end{array}$ & $\begin{array}{l}30<\mathrm{BMI}<35 \\
96 \% \text { improvement } \\
\text { Of metabolic status }\end{array}$ \\
\hline Sultan et al.[20] & 95 LAGB & 5 & $<6$ & $\begin{array}{l}40 \% \text { complete } \\
40 \% \text { partial }\end{array}$ & Mean BMI 46.3 \\
\hline Scopinaro et al.[16] & $312 \mathrm{BPD}$ & 10 & ND & $97 \%$ & \\
\hline Pontiroli et al.[16] & $\begin{array}{l}23 \text { BPD } \\
78 \text { LAGB } \\
37 \text { control }\end{array}$ & 5.5 & ND & $\begin{array}{l}100 \% \\
66 \% \\
\text { none }\end{array}$ & \\
\hline Marceau et al.[16] & 1356 DS (377 T2DM & 7 & ND & $92 \%$ & \\
\hline
\end{tabular}

BPD - biliopancreatic diversion, LAGB - laparoscopic gastric band, RYGB - Roux-en-Y gastric bypass, LSG laparoscopic sleeve gastrectomy, DS duodenal switch, ND not defined.

A meta-analysis conducted by Zh. Khorgami et al. (2019) showed that within 2 years, 138 patients out of 263 who underwent surgery experienced remission of type 2 diabetes, compared to 7 out of 200 who received medication only. There was also a more significant decrease in $\mathrm{HbA} 1 \mathrm{C}$, serum glucose, increased HDL, and decreased triglycerides [24].

Bariatric operations that are the subject of the analysis are divided into restrictive (sleeve gastrectomy (SG) and regulated gastric banding (GB), malabsorption (intestinal bypass anastomosis), and combined, as well as combined/restrictive and malabsorbing (Roux-en-Y gastric bypass (RYGB) and biliopancreatic bypass with or without a duodenal switch, BPD or BPD-DS).

Studies have found $[13,14]$ that remission of DM2 occurs in $66 \%, 45 \%, 80-85 \%$, and $95 \%$ of patients after SG, GB, RYGB, and BPD-DS, respectively. The mechanism of remission of DM2 after bariatric surgery is still debated.

Thus, the most effective procedures for the induction of remission in type 2 DM are RYGB and BPD-DS [19-23]. Both procedures involve the exclusion of the duodenum from the digestive process and this mechanism was assumed to be required the effect of the operation, which has been confirmed by experimental studies by Rubino and Marescaux [30]. However, another anatomical effect of these operations is the accelerated discharge of partially digested nutrients and their contact with the distal segment of the small intestine, the ileum, which contributes to the secretion of peptides of intestinal origin involved in glucose homeostasis [9].

To study the role of the distal segment of the ileum in RYGB surgery, the ileal transposition operation is used in the experiment [31], and the authors have shown that the procedure itself induces remission of type 2 diabetes and weight loss without a component of disabling the duodenum [32], but this opinion is controversial.

The ileal transposition (Figure 1), as an experimental operation, has found its origin in the work of $\mathrm{H}$. Koopmans et al. (1982), who, while studying the effects of a jejunoileal bypass, particularly, a decrease in food intake, suggested the presence of an endogenous signal from the distal segments of the ileum in response to stimulation by food masses. In order to confirm this assumption in the experiment, the authors performed a resection of 10-20 cm of the distal part of the ileum in rats, followed by its movement on the neurovascular bundle to the proximal segments of the jejunum. The procedure was called the ileal transposition, and for the first time, there was a decrease in the amount of food consumed, body weight, glucose, triglycerides, and cholesterol levels with a preserved length of the small intestine [8]. 
Figure 1 - Scheme of Ileal transposition
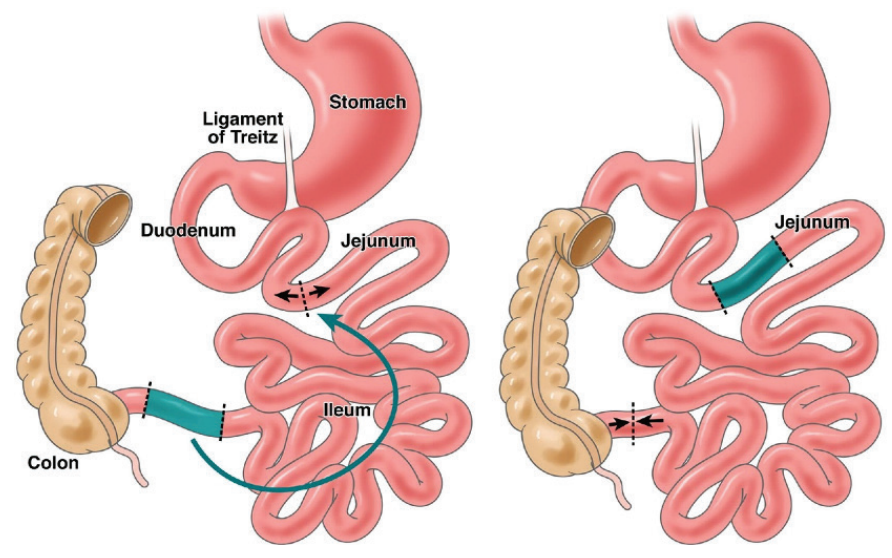

Some clinical studies combined the ileal transposition with gastric bypass surgery or sleeve gastrectomy [33-36]. During a study of the metabolic effects of the ileal transposition in combination with elevating sleeve gastrectomy (DSG) in 159 patients with obesity and DM2, Celik et al. found a decrease in the average body mass index (BMI) from 39.33 to 25.51, the average fasting glucose level from 189.9 to $123.5 \mathrm{mg} / \mathrm{dL}$, and the average HbA1c level from $9.24 \%$ to $6.14 \%$ a year after surgery [31].

The "Hindgut" hypothesis tries to explain the metabolic effects of the ileal transposition and states that the improvement in metabolic control is due to an increase in the flow of unabsorbed nutrients in the distal segment of the small intestine. Which leads to the activation of a neuroendocrine negative feedback mechanism often referred to as the "ileal inhibitor." This thesis is proved by the established effects of displacement of the distal segment of the small intestine in the experiment, i.e. the increase in the number and secretory activity of L-cells of the displaced segment of the intestine, increase in the secretion of glucagonlike peptide 1 and -2 (GLP-1, GLP-2), peptide tyrosine-tyrosine (PYY), increase in the mass of $\beta$-cells of the pancreas, decrease in their apoptosis and increase in insulin production, and increase in glucose tolerance $[38,39,40]$.

GLP-1 increases glucose-induced insulin secretion, inhibits glucagon secretion, reduces food absorption, improves insulin sensitivity, promotes $\beta$-cell regeneration, and reduces their apoptosis, this is how its antidiabetic effect is manifested [41]. PYY, as well as GLP-1, is characterized by stimulation of $\beta$-cell regeneration and hypoglycemic effect. Moreover, it participates in the regulation of appetite by reducing it [42].

Another effect of the ileal transposition is to reduce gluconeogenesis and lipogenesis in the liver. In a study by Hung C. et al., the following was observed in rats after the ileal transposition: undigested food passing into the gut lumen triggered the production of chemokines, which reached the liver via the portal vein, therefore, it led to a decrease in the synthesis of glucose and lipogenesis in the body by attenuation of signaling via TGF- $\beta$ and, consequently, a decrease in the level of hyperglycemia.

The ileal transposition proved to be the most successful metabolic operation in the correction of severe forms of nonobese DM2 in the experiment [43].

In addition, some authors express doubts about the pathophysiological importance of the hypothesis «Hindgut», which is due to the absence of an effect equivalent to metabolic operations in response to antidiabetic drugs stimulating secretion GLP-1 [44]. In contrast to the positive effects of the incretion mechanism and the hypothesis «Hindgut», it is assumed that there are hormonal pathways with adverse effects for glycemic homeostasis, the so-called anti-incretine mechanism, which is launched in response to the passage of nutrients through the proximal sections of the small intestine and the presence of which explains the opposite «Foregut» theory. The anti-incretin effect is expressed in the inhibition of the incretin effect: it causes a decrease in insulin release, a decrease in beta cell proliferation, and inhibition of insulin action to prevent hypoglycemia. $[45,46,47]$.

In this case, it is interesting to study the effects of IT and to develop innovative experimental operational methods, which make it possible to assess changes in the parameters of glycometabolism on DM models with the exception of the antiincretin mechanism.

\section{The Effectiveness of Bariatric Surgery in DM1.}

To date, there is evidence that metabolic operations may improve the condition of patients with DM1 but the data of various authors are contradictory and further research is needed $[15,17]$ in this field.

Initially, it was suggested that the improvement in the condition of patients with DM1 and their increased sensitivity to insulin is due to weight loss after bariatric surgery $[48,49]$. Currently, the Hussain study (2019) is known, which investigated changes in HBA1c, BMI, and the daily dose of insulin replacement therapy after bariatric interventions in patients with DM1. A decrease in these indicators was revealed but they were statistically unreliable for glycolized hemoglobin. A weak correlation between insulin dose and BMI, as well as a slight correlation between HBA1c and BMI after surgery, was found. According to the author, this dictates the need for further investigation of glucose homeostasis depending on the anatomical changes in the gastrointestinal tract caused by metabolic surgery since each centimeter of the gastrointestinal tract is a complex functional unit, thus, any change affects homeostasis [21].

Nevertheless, A. Chow et al., having conducted a metaanalysis, obtained statistically reliable results. The authors analyzed 13 papers describing the results of Roux-en-Y gastric bypass surgery in 86 patients with obesity and type 1 diabetes mellitus. It was found that their BMI $(p<0.00001)$, the need for insulin $(p<0.00001)$, and the level of glycolized hemoglobin $(p<0.01)$ decreased. However, the target value of HBA1c $\leq 7.0 \%$ was not reached. According to the authors, this was due to an increase in the tolerance of the liver and peripheral tissues to insulin, instead of the effect of GLP-1 on the functions of the endocrine part of the pancreas since patients with DM1 had almost zero functional potential of beta cells [23].

According to Ahn C. H. et al. (2020), the ileal transposition slows the physiological aging of pancreatic $\beta$-cells in obese rats, which may contribute to an increase in insulin release following a meal. The mechanism underlying the prevention of the $\beta$-cell aging after the ileal transposition may be a new therapeutic target for diabetes mellitus.

It can be concluded that the metabolic effects of the ileal transposition cannot positively affect glycemic control in cases with minimal or zero $\beta$-cell functioning in patients with DM1. However, there is an assumption that islet cell regeneration occurs even in patients with long-term DM1. Therefore, the timing of bariatric surgery is crucial since effects mediated by the ileal transposition may contribute to the preservation of $\beta$-cell mass [50-52]. 


\section{Conclusion}

Interest in metabolic surgery for diabetes mellitus is growing from year to year. Particularly, when searching for the key expression of "ileal transposition," more than 300 publications are found in the Pubmed (US National Library of Medicine National Institutes of Health) database. The growth trend of publications has an upward exponential dependence.

Modern bariatric procedures, such as RYGB, BPD/DS and transit bipartition, which involve the mechanism of accelerated intake of undigested nutrients to the terminal segments of the small intestine, are the most effective in the correction of morbid obesity and DM. Changes in the anatomy of the gastrointestinal tract during bariatric surgery mediate changes in hormonal regulation that contribute to the remission of diabetes, which requires further study by experimental operations.

Given the absence of an implemented surgical method for the treatment of diabetes mellitus without morbid obesity in clinical practice, the inconsistency and lack of data on the positive metabolic effects of the ileal transposition, it seems appropriate to further study the mechanisms of homeostasis of glucose during experimental operations.

\section{References}

1. Global report on diabetes. WHO, 2016. [Electronic resource]. - Access mode: https://www.who.int/diabetes/global-report/ru/

2. Foster D, Sanchez-Collins S, Cheskin LJ. Erratum: multidisciplinary team-based obesity treatment in patients with diabetes: current practices and the state of the science. Diabetes Spectr. 2017; 30: 244-249. https://doi.org/10.2337/ds18-er01

3. Estimated global healthcare expenditure to treat diabetes in 2019 and 2045, 2019. [Electronic resource]. - Access mode: https://www. statista.com/statistics/241820/estimated-global-healthcare-expenditures-to-treat-diabetes.

4. Chamberlain JJ. et al. Diagnosis and management of diabetes: synopsis of the 2016 American Diabetes Association Standards of Medical Care in Diabetes. Ann. Intern. med. 2016; 19;164(8):542-52 https://doi.org/10.7326/M15-3016

5. Pugliese G, Vitale M, Resi V, Orsi E. Is diabetes mellitus a risk factor for CoronaVIrus Disease 19 (COVID-19)? Acta Diabetol. 2020; 57:1275-1285. https://doi.org/10.1007/s00592-020-01586-6

6. Affinati AH, Esfandiari NH, Oral EA, Kraftson A. T. Bariatric Surgery in the Treatment of Type 2 Diabetes. Curr. Diabetes Rep. 2019; 19(12): 156. https://doi.org/10.1007/s11892-019-1269-4

7. Pappachan JM, Viswanath AK. Medical management of diabesity: do we have realistic targets? Curr. Diabetes Rep. 2017 ; $17(1): 4$. https://doi.org/10.1007/s11892-017-0828-9

8. Kornyushin OV, Galagudza MM., Neimark AE, Babenko AYu, Grineva E.N. Ileal transposition in surgical treatment for type 2 diabetes mellitus [in Russian]. Diabetes Mellitus. 2015; 18:58-64. https://doi.org/10.14341/DM2015158-64

9. Ersoz F, Duzkoylu Y, Deniz MM, Boz M. Laparoscopic Roux-en-Y gastric bypass with ileal transposition - an alternative surgical treatment for type 2 diabetes mellitus and gastroesophageal reflux. Wideochir Inne Tech Maloinwazyjne. 2015; 10:481-5. https://doi. org/10.5114/wiitm.2015.54224

10. Ahuja A, Tantia O, Chaudhuri T, Shashi K, Shivakumar S, Kajari M et al. Predicting remission of diabetes post metabolic surgery: a comparison of ABCD, diarem, and DRS scores. Obes Surg. 2018; 28:2025-31. https://doi.org/10.1007/s11695-018-3136-9

11. Park CH, Nam SJ, Choi HS, Kim KO, Kim DH et al. Korean Research Group for Endoscopic Management of Metabolic Disorder and Obesity. Comparative Efficacy of Bariatric Surgery in the Treatment of Morbid Obesity and Diabetes Mellitus: a Systematic Review and Network Meta-Analysis. Obes Surg. 2019; 29(7): 2180-2190. https://doi.org/10.1007/s11695-019-03831-6

12. Praveen Raj P, Bhattacharya S, Saravana Kumar S, Sabnis SC, Parthasarathi R, Swamy PDK, et al. Do Bariatric Surgery-Related Type 2 Diabetes Remission Predictors Add Clinical Value? A Study on Asian Indian Obese Diabetics. Obes Surg. 2017; 27: 2113-9. https://doi. org/10.1007/s11695-017-2615-8

13. Lee WJ, Chong K, Chen SC, James Z, Kong-Han S, Lee YCh, et al. Preoperative Prediction of Type 2 Diabetes Remission After Gastric Bypass Surgery: a Comparison of DiaRem Scores and ABCD Scores. Obes Surg. 2016; 26: 2418-24. https://doi.org/10.1007/s11695016-2120-5

14. Min T, Barry JD, Stephens JW. Predicting the Resolution of Type 2 Diabetes after Bariatric Surgical Procedures: A Concise Review. Diabetes Metab. 2015; 6:1-5. https://doi.org/10.4172/2155-6156.1000617

15. Adams TD, Davidson LE, Litwin SE, et al. Health benefits of gastric bypass surgery after 6 years. JAMA. 2012;308:1122-31. https://doi. org/10.1001/2012.jama.11164

16. Brethauer SA, Aminian A, Romero-Talamás H, et al. Can diabetes be surgically cured? Long-term metabolic effects of bariatric surgery in obese patients with type 2 diabetes mellitus. Ann Surg. 2013; 258(4):628-36. discussion 636-7. https://doi.org/10.1097/ SLA.0b013e3182a5034b

17. Cohen RV, Pinheiro JC, Schiavon CA, et al. Effects of gastric bypass surgery in patients with type 2 diabetes and only mild obesity. Diabetes Care. 2012; 35:1420-8. https://doi.org/10.2337/dc11-2289

18. Lakdawala M, Shaikh S, Bandukwala S, et al. Roux-en-Y gastric bypass stands the test of time: 5-year results in low body mass index (30$35 \mathrm{~kg} / \mathrm{m} 2$ ) Indian patients with type 2 diabetes mellitus. Surg Obes Relat Dis. 2013; 9:370-8. https://doi.org/10.1016/j.soard.2012.07.017

19. Heneghan HM, Cetin D, Navaneethan SD, et al. Effects of bariatric surgery on diabetic nephropathy after 5 years of follow-up. Surg Obes Relat Dis. 2013; 9:7-14. https://doi.org/10.1016/j.soard.2012.08.016

20. Sultan S, Gupta D, Parikh M, et al. Five-year outcomes of patients with type 2 diabetes who underwent laparoscopic adjustable gastric banding. Surg Obes Relat Dis. 2010; 6:373-376. https://doi.org/10.1016/j.soard.2010.02.043

21. Hussain A. The effect of metabolic surgery on type 1 diabetes: meta-analysis. Arch endocrin metab. 2018; 62:172-8. http://dx.doi. org/10.20945/2359-3997000000021

22. Mottalib A, Kasetty M, Mar JY, Elseaidy T, Ashrafzadeh S, Hamdy O. Weight Management in Patients with Type 1 Diabetes and Obesity. Curr. Diabetes Rep. 2017; 17:92. https://doi.org/10.1007/s11892-017-0918-8

23. Chow A, Switzer NJ, Dang J, Xinzhe S, de Gara Ch, Birch DW, et al. A Systematic Review and Meta-analysis of outcomes for Type 1 diabetes after bariatric surgery. J. Obes. 2016; 6170719. https://doi.org/10.1155/2016/6170719 
24. Khorgami Z, Shoar S, Saber AA, Howard CA, Danaei G, Sclabas GM. Outcomes of bariatric surgery versus medical management for type 2 diabetes mellitus: a meta-analysis of randomized controlled trials. Obes surg. 2019; 29:964-974. https://doi.org/10.1007/s11695018-3552-x

25. Quevedo M, Palermo M, Serra E, Ackermann MA. Metabolic surgery: gastric bypass for the treatment of type 2 diabetes mellitus. Transl. Gastroenterol. Hepatol. 2017; 2(6):58. https://doi.org/10.21037/tgh.2017.05.10

26. Wang JL., Xu XH, Zhang XJ, Li WH. The role of obestatin in roux-en-Y gastric bypass-induced remission of type 2 diabetes mellitus. Diabetes Metab Res Rev. 2016; 32:470-7. https://doi.org/10.1002/dmrr.2735

27. Argyropoulos G. Bariatric Surgery: Prevalence, predictors, and mechanisms of diabetes remission. Curr. Diab. Rep. 2015; 15:15. https:// doi.org/10.1007/s11892-015-0590-9

28. Esposito K, Maiorino MI, Petrizzo M, Bellastella G, Giugliano D. Remission of type 2 diabetes: Is bariatric surgery ready for prime time? Endocrine. 2015; 48:417-421. https://doi.org/10.1007/s12020-014-0463-Z

29. Hutch CR., Sandoval D. The Role of GLP-1 in the Metabolic Success of Bariatric Surgery. Endocrinology. 2017; 158:4139-4151. https:// doi.org/10.1210/en.2017-00564

30. Buchwald H, Buchwald JN. Metabolic (bariatric and nonbariatric) surgery for type 2 diabetes: a personal perspective review. Diabetes Care. 2019; 42(2):331-340. https://doi.org/10.2337/dc17-2654

31. Ahn CH, Chae S, Oh TJ, Hwang D, Cho YM. Dynamic Adaptive Changes of the Ileum Transposed to the Proximal Small Intestine in Rats. Obes Surg. 2019; 29:2399-2408. https://doi.org/10.1007/s11695-019-03858-9

32. Boza C, Muñoz R, Yung E, Milone L, Gagner M. Sleeve Gastrectomy with Ileal Transposition (SGIT) Induces a Significant Weight Loss and Diabetes Improvement Without Exclusion of the Proximal Intestine. J. Gastrointest. Surg. 2011; 15(6):928-934. https://doi. org/10.1007/s00464-007-9685-y

33. Oh TJ, Ahn CH, Cho YM. Contribution of the distal small intestine to metabolic improvement after bariatric/metabolic surgery: Lessons from ileal transposition surgery. J Diabetes Investig. 2016; 7(1):94-101. https://doi.org/10.1111/jdi.12444

34. Yan K, Chen W, Zhu H, Lin G, Pan H, Li N, et al. Ileal Transposition Surgery Decreases Fat Mass and Improves Glucose Metabolism in Diabetic GK Rats: Possible Involvement of FGF21. Front Physiol. 2018; 9:191. https://doi.org/10.3389/fphys.2018.00191

35. Gao Z, Wang B, Gong X, Yao C, Ren D, Shao L, et al. Effect of gastric bypass combined with ileal transportation on type 2 diabetes mellitus. Exp Ther Med. 2018; 15:4571-7. https://doi.org/10.3892/etm.2018.5928

36. Celik A, Asci M, Celik BO, Ugale S. The impact of laparoscopic diverted sleeve gastrectomy with ileal transposition (DSIT) on short-term diabetic medication costs. Springerplus. 2015; 4:417. https://doi.org/10.1186/s40064-015-1216-Z

37. Celik A, Ugale S, Ofluoglu H, Vural E, Cagiltay E, Cat H, et al. Metabolic Outcomes of Laparoscopic Diverted Sleeve Gastrectomy with Ileal Transposition (DSIT) in Obese Type 2 Diabetic Patients. Obes Surg. 2015; 25:2018-22. https://doi.org/10.1007/s11695-015-1671-1

38. Kornyushin OV, Bakhtyukov AA, Zorina I., Toropova YaG, Derkach KV, Berko OM, et al. The effect of different types of bariatric surgery on the metabolic and hormonal parameters in rats with decompensed form of type 2 diabetes mellitus [in Russian]. Adv Gerontol. 2019; 32(1-2):85-92. https://doi.org/10.1134/S2079057019030081

39. Mufide NA, Erdem K, Ali A. Bariatric/Metabolic Surgery in Type 1 and Type 2 Diabetes Mellitus. Eurasian J Med. 2019; 51(1): 85-89. https://doi.org/10.5152/eurasianjmed.2018.18298.

40. Moreno-Fernandez J, Chico A. Bariatric surgery results in patients with type 1 diabetes mellitus on continuous subcutaneous insulin infusion therapy. Endocrinol Nutr. 2016; 63:571-2. https://doi.org/10.1016/j.endonu.2016.09.002

41. Prada-Oliveira JA, Camacho-Ramirez A, Salas-Alvarez J, Campos-Martinez FJ, Lechuga-Sancho AM, Almorza-Gomar D. et al. GLP-1 mediated improvement of the glucose tolerance in the T2DM GK rat model after massive jejunal resection. Ann Anat. 2019; 223:1-7. https://doi.org/10.1016/j.aanat.2019.01.007

42. Guida C, Stephen S, Guitton R, Ramracheya RD. The Role of PYY in Pancreatic Islet Physiology and Surgical Control of Diabetes. Trends Endocrinol Metab. 2017; (8):626-636. https://doi.org/10.1016/j.tem.2017.04.005

43. Hung C, Napoli E, Ross-Inta C, Graham J, Flores-Torres AL, Stanhope KL. et al. Ileal interposition surgery targets the hepatic TGF- $\beta$ pathway, influencing gluconeogenesis and mitochondrial bioenergetics in the UCD-T2DM rat model of diabetes. FASEB J. 2019; 33(10):11270-11283. https://doi.org/10.1096/fj.201802714R

44. Amouyal C, Andreelli F. Increasing GLP-1 circulating levels by bariatric surgery or by GLP-1 receptor agonists therapy: why are the clinical consequences so different? J Diabetes Res. 2016; 2016: 5908656. https://doi.org/10.1155/2016/5908656

45. Rubino F, Marescaux J. Effect of duodenal-jejunal exclusion in a non-obese animal model of type 2 diabetes: A new perspective for an old disease. Ann. Surg. 2004; 239:1-11. https://doi.org/10.1097/01.sla.0000102989.54824.fc

46. Rubino F, Forgione A, Cummings DE, Vix M, Gnuli D, Mingrone G, et al. The mechanism of diabetes control after gastrointestinal bypass surgery reveals a role of the proximal small intestine in the pathophysiology of type 2 diabetes. Ann. Surg. 2006; 244:741-749. https://doi. org/10.1097/01.sla.0000224726.61448.1b

47. Buchwald H, Estok R, Fahrbach K, Banel D, Jensen MD, Pories WJ, et al. Weight and Type 2 diabetes after bariatric surgery: systematic review and meta-analysis. Am J Med. 2009; 122:248-56. https://doi.org/10.1016/j.amjmed.2008.09.041

48. Hironaka J, Kitahama S, Sato H, Inoue M, Takahashi T, Tamori Y. Sleeve Gastrectomy Induced Remission of Slowly Progressive Type 1 Diabetes in a Morbidly Obese Japanese Patient. Intern Med. 2019; 58(5):675-678. https://doi.org/10.2169/internalmedicine.1217-18

49. Robert M, Belanger P, Hould FS, Marceau S, Tchernof A, Biertho L. Should metabolic surgery be offered in morbidly obese patients with type i diabetes? Surg Obes Relat Dis. 2015; 11(4):798-805. https://doi.org/10.1016/j.soard.2014.12.016

50. Mikhaylichenko VYu, Stolyarov SS, Starykh AA. Pathophysiological aspects of the development of alloxan diabetes mellitus in rats in experiment. Modern Problems of Science and Education. 2015; (5): 23. https://www.elibrary.ru/item.asp?id=32663884

51. Ighodaro OM, Adeosun AM, Akinloye OA. Alloxan-induced diabetes, a common model for evaluating the glycemic-control potential of therapeutic compounds and plants extracts in experimental studies. Medicina. 2017; 53(6):365-374. https://doi.org/10.1016/j. medici.2018.02.001

52. Ahn CH, Choi EH, Oh TJ, Cho YM. Ileal Transposition Increases Pancreatic $\beta$-Cell Mass and Decreases $\beta$-Cell Senescence in DietInduced Obese Rats. Obes surg 30. 2020; 1849-1858. https://doi.org/10.1007/s11695-020-04406-6 